\title{
Effect of male child preference on the decision making of women in choosing contraception
}

\author{
Varuna Pathak, Ruchika Arya*
}

Department of Obstetrics and Gynecology, Sultania Zanana Hospital, Gandhi Medical College, Bhopal, Madhya Pradesh, India

Received: 10 February 2018

Accepted: 23 February 2018

\section{*Correspondence:}

Dr. Ruchika Arya,

E-mail: ruchikaarya89@gmail.com

Copyright: (c) the author(s), publisher and licensee Medip Academy. This is an open-access article distributed under the terms of the Creative Commons Attribution Non-Commercial License, which permits unrestricted non-commercial use, distribution, and reproduction in any medium, provided the original work is properly cited.

\begin{abstract}
Background: Pressures resulting from unrestrained human population growth put demands on the natural world that can overwhelm any efforts to achieve a sustainable future. If we are to halt the destruction of our environment, we must accept limits to that growth. In this hospital based study, we aim to study the factors that influence the choice of contraception. Purpose of this study is to analyze the contraceptive behavior which is a product of many determinants such as age, religion, education, parity, fertility, child care support, economic and social circumstances, motivation, communication and the perception of reliability and safety of a chosen method thereby ensuring better health for the mother and better care and upbringing of children.

Methods: The present study entitled effect of male child preference on the decision making of women in choosing contraception is a cross sectional study carried out on 700 subjects in Department of Obstetrics and Gynaecology, Sultania Zanana Hospital, Gandhi Medical College, Bhopal. Study population includes women of reproductive age group who came to seek contraceptive advice from family planning OPD of the hospital.

Results: Subjects having 2 male children preferred permanent method of contraception (66\%) as compared to subjects having 2 female children $(7.93 \%)$, this result is statistically significant $(\mathrm{p}<0.05)$ showing a strong preference for male child in Indian society.

Conclusions: The results indicated that a woman's desire to limit family size with preferred sex composition of children, coupled with her autonomy and the socio cultural context, are the major determinants of contraceptive method choices.
\end{abstract}

Keywords: Contraceptive method, Contraception, Male child preference, Socio cultural context

\section{INTRODUCTION}

Pressures resulting from unrestrained human population growth put demands on the natural world that can overwhelm any efforts to achieve a sustainable future. If we are to halt the destruction of our environment, we must accept limits to that growth."

Although the Family Planning 2020 (FP2020) global movement has focused attention on improving access to modern contraception among the world's poorest women, evidence suggests this goal is still far from reality. ${ }^{1}$

The high rate of unintended pregnancy is said to be driving population growth, where approximately one-half of all pregnancies are reported to be unintended, that is they came too soon or were unwanted.

These pregnancies can be prevented with increased access to effective family planning methods. Contraception methods can prevent at least $25 \%$ of all 
maternal deaths by allowing women to prevent unintended pregnancies and unsafe abortions, and to protect themselves from sexually transmitted diseases. ${ }^{2}$

In this hospital based study, we aim to study the effect of male child preference on the decision making of women in the choice of contraception. Purpose of this study is to analyse the contraceptive behavior which is a product of many determinants such as age, religion, education, parity, fertility, child care support, economic and social circumstances, motivation, communication and the perception of reliability and safety of a chosen method thereby ensuring better health for the mother and better care and upbringing of children.

\section{METHODS}

The present study is a cross sectional study carried out at Department of Obstetrics and Gynecology, Sultania Zanana Hospital, Gandhi Medical College, Bhopal from $1^{\text {st }}$ November 2015 to $31^{\text {st }}$ March 2017. Women of reproductive age group who came to seek contraceptive advice from family planning OPD of Sultania Zanana Hospital, Bhopal. Sample size was 700 subjects.

Data was collected from consenting females with the help of predesigned, preformed questionnaire by interview technique and their proforma was filled.

Counseling regarding various contraceptive methods was done. Method for obtaining information on the study was recall method.

\section{Inclusion criteria}

- Women giving informed consent.

- Women in reproductive age group.

- Women seeking contraceptive advice.

\section{Exclusion criteria}

- Pregnant women.

\section{Statistical analysis}

Data collected was tabulated and compiled in MS excel. Chi square test was used to estimate the significance value. For analysis $<0.05$ was considered to be significant.

\section{RESULTS}

Majority of the study subjects were young reproductive women in the age group of 25-29 years (40.29\%).

Most of the subjects using permanent method of contraception were more than 30years old while majority of the subjects using temporary method of contraception were less than 30years old.

Table 1 shows distribution of the total subjects according to number of male children: subjects having no male child were $25.29 \%$, 1 male child $53.43 \%, 2$ male child $18 \%, 3$ male child $3.28 \%$.

Table 1: Distribution of subjects according to number of male child.

\begin{tabular}{|lll|}
\hline No. of male child & No. of subjects & $\%$ \\
\hline 0 & 177 & 25.29 \\
\hline 1 & 374 & 53.43 \\
\hline 2 & 126 & 18 \\
\hline 3 & 23 & 3.28 \\
\hline Total & 700 & 100 \\
\hline
\end{tabular}

Table 2 shows distribution of subjects according to number of female children: subjects having no female child were $27.43 \%, 1$ female child $47.28,2$ female child $20.43 \%, 3$ female child $4.29 \%$, 4 female child $0.57 \%$.

Table 2: Distribution of subjects according to number of female child.

\begin{tabular}{|c|c|c|}
\hline No. of female child & No. of subjects & $\%$ \\
\hline 0 & 192 & 27.43 \\
\hline 1 & 331 & 47.28 \\
\hline 2 & 143 & 20.43 \\
\hline 3 & 30 & 4.29 \\
\hline 4 & 4 & 0.57 \\
\hline Total & 700 & 100 \\
\hline
\end{tabular}

Table 3 and 4 signifies that subjects having 0 male child preferentially use temporary method (Barrier, OCP, IUCD) of contraception and subjects having 1or more male child preferentially use permanent method (tubectomy) of contraception. Chi square value 202.5315. $P$ value $<0.00001$.

Table 3: Relation between number of male child and various contraceptive methods.

\begin{tabular}{|lllllllllll|}
\hline No. of male child & No. of subjects & Barrier & Barrier \% & IUCD & IUCD \% & OCP & OCP \% & TT & TT \% \\
\hline Nil & 177 & 66 & 37.29 & 37 & 20.90 & 66 & 37.29 & 8 & 4.52 & \\
\hline 1 male & 374 & 118 & 31.55 & 56 & 14.97 & 125 & 33.42 & 75 & 20.05 \\
\hline 2 male & 126 & 20 & 15.87 & 6 & 4.76 & 12 & 9.52 & 88 & 69.84 \\
\hline 3 male & 23 & 4 & 17.39 & 0 & 0 & 1 & 4.35 & 18 & 78.26 \\
\hline
\end{tabular}


Table 4: Relation between number of female child and various contraceptive methods.

\begin{tabular}{|llllllllll|l|}
\hline No. of female child & No. of subjects & Barrier & Barrier \% & Iucd & Iucd \% & OCP & OCP & TT & TT\% \\
\hline Nil & 192 & 56 & 29.17 & 20 & 10.42 & 72 & 37.50 & 44 & 22.91 \\
\hline 1 Female & 331 & 103 & 31.12 & 45 & 13.59 & 94 & 28.40 & 89 & 26.89 \\
\hline 2 Female & 143 & 40 & 27.97 & 33 & 23.08 & 30 & 20.98 & 40 & 27.97 \\
\hline 3 Female & 30 & 9 & 30 & 1 & 3.33 & 8 & 26.67 & 12 & 40 \\
\hline 4 Female & 4 & 0 & 0 & 0 & 0 & 0 & 0 & 4 & 100 \\
\hline
\end{tabular}

Result is statistically significant showing male child preference prevalent in Indian society.

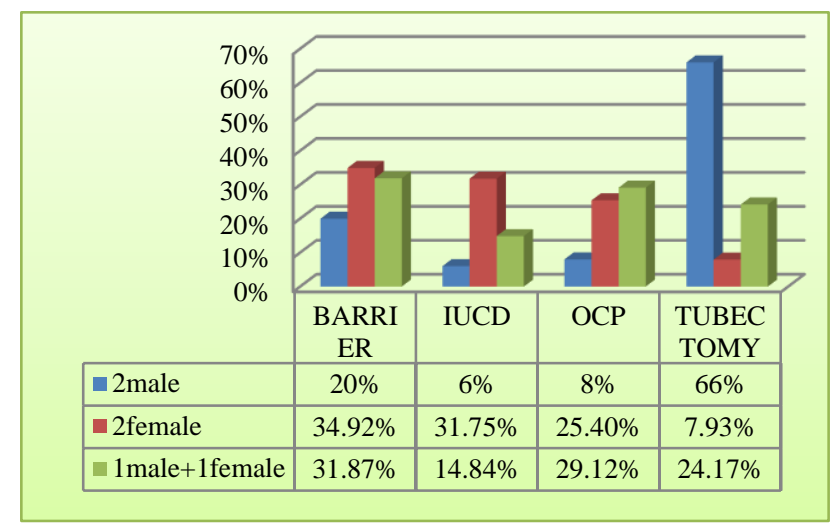

Figure 5: Various contraceptive methods choices after 2 children.

According to Figure 5, total number of subjects having 2 male children were 50 and among them temporary method of contraception was used by $34 \%$ (barrier $20 \%$, IUCD $6 \%$, OCP 8\%), and permanent method of contraception was used by $66 \%$. Total number of subjects having 2 female children were 63 and among them temporary method of contraception was used by $92.07 \%$ (barrier $34.92 \%$, IUCD $31.75 \%$, OCP $25.40 \%$ ), and permanent method of contraception was used by $7.93 \%$.

Chi square statistic 42.1066.P value is $<0.05$. Result is statistically significant.

Suggesting that subjects having 2 male children prefer permanent method of contraception as compared to subjects having 2 female children, showing a strong preference for male child in Indian society.

\section{DISCUSSION}

In present study majority of the subjects using permanent method of contraception were in the age group of $>30$ years old. Majority of the subjects using temporary method of contraception were <30years old.

According to P.Shukla et al $40.75 \%$ of respondents used temporary methods in the age group of 26-30 years and
$71.87 \%$ of respondents used permanent method of contraception in the age group of 36-40 years. ${ }^{3}$

In present study subjects having 2 male children prefer permanent method of contraception $(66 \%)$ as compared to subjects having 2 female children $(7.93 \%)$ Result is statistically significant $(\mathrm{p}<0.05)$ showing a strong preference for male child in our society.

According to NFHS 3 use of contraceptive varies greatly with parity, first increasing from $34 \%$ for women with one child to $74 \%$ for women with three children. At each parity women who have sons were much more likely than women who have no sons to be using contraception. ${ }^{4,5}$

In a study by Bose $\mathrm{S}$ et al the root of son preference in India lies in deeply entrenched social, cultural, and economic discrimination against women and girls and there is evidence that this type of gender bias is increasing and spreading in modern India. ${ }^{6}$

Boy preference is so ingrained in the Indian family system that many women do not feel that they have done their wifely duty until they produce a son. The only way they feel their life is fulfilled is if they produce a son. ${ }^{7}$

In a study by Chan CL et al the overall implication of a decreased sex ratio and female feticide is the low value of the girl child, the resulting exploitation of women and violence against women. The health implications of gender bias result in higher girl child mortality and morbidity. ${ }^{8}$ A concern has also been raised of social unrest that may result from unequal population of sexes. ${ }^{8}$

In a study by Sudha $S$ et al a preference for the male children was documented by the fact that the preference for two male siblings was higher than for two female siblings and there were more families with no daughters as compared to those with no sons.

The prevailing gender bias for male children is one of the major problems in the Indian society was also documented by other studies. ${ }^{9}$ India on the whole is a patriarchal society. Women too value their sons more, as they perceive the son to be a major source of support in the future. Women are inculcated often by women themselves to believe their value is attached to men. Study by Arnold F et al have shown that gender bias is 
not motivated by economic hardship but rather by cultural factors. ${ }^{10}$

With increasing birth order the number of female children increased. It could be stipulated that the families with daughters had more children with the hope of having sons. This leads to an increased number of female births, a paradoxical gain for the female population.

\section{CONCLUSION}

India is making progress towards reduced maternal mortality and improved access to reproductive health care. However, evidence shows that the progress made is uneven and inequitable.

The objective of this study was to study the socio demographic determinants influencing the decision making of women in choosing contraception and to address the gender bias in our society. The results indicated that a woman's desire to limit family size with preferred sex composition of children, coupled with her autonomy and the socio cultural context, are the major determinants of contraceptive method choices

It is important to focus on high unmet need for family planning and contraceptives with an inclusive policy focusing on its poorest section. If the goal is to create a demand for adoption of family planning and services, a check in the potential future unmet category is needed. A simultaneous attention to the health systems strengthening component is crucial for ensuring sustained delivery of good-quality services.

Development of the family planning strategy is an important milestone and should be followed up with implementation, resource allocation, and equity-based monitoring and evaluation. Reproductive health programmes should address the socioeconomic barriers and consider multiple cost-effective strategies to promote awareness regarding contraception.

Funding: No funding sources Conflict of interest: None declared

Ethical approval: The study was approved by the Institutional Ethics Committee

\section{REFERENCES}

1. Family Planning 2020 (FP2020) FP2020 commitment to action 2014-2015. New York: FP2020;2015. Available at http://www.familyplanning2020.org/resources/13569

2. Paxman J, Rizo A, Brown L, Benson J. The clandestine epidemic: the practice of unsafe abortion in Latin America. Stud Fam Plan. 1993;24:206-14.

3. Shukla P. A study on utilization of family planning practices and there side effect among the urban slum population. J Com Med. 2010;6(1).

4. Govt of India (2012). Census 2011, provisional population report, office of the registrar general and census commissioner India, Ministry of Home Affairs. 2011. Available at http://censusindia.gov.in/2011-provresults/indiaatglance.html

5. National family health survey NFHS-3 India 200506 international institute for population sciences, Mumbai, India measure DHS+ ORS\&MARCO. Available https://dhsprogram.com/pubs/pdf/FRIND3/FRIND3Vol1AndVol2.pdf

6. Bose S, Trent K. Socio-demographic determinants of abortion in India: A North-South comparison. J Biosoc Sci. 2006;38:261-82.

7. Gentleman A. India's lost daughters: Abortion toll in millions. The New York Times. 2006 Jan 9. Available http://www.nytimes.com/2006/01/09/world/asia/indi as-lost-daughters-abortion-toll-in-millions.html

8. Chan CL, Yip PS, Ng EH, Ho PC, Chan CH, Au JS. Gender Selection in China: its meaning and implications. J Assist Reprod Genet. 2002;19:426-30

9. Sudha S, Indaya RS. Female demographic disadvantage in India 1981-1991. Sex selective abortions and female infanticide. Dev Change. 1999;30:585-618.

10. Arnold F, Kishore S, Roy TT. Sex selective abortions. Popul Dev Rev. 2002;28:759-85.

Cite this article as: Pathak V, Arya R. Effect of male child preference on the decision making of women in choosing contraception. Int J Reprod Contracept Obstet Gynecol 2018;7:1336-9. 